Article

\title{
Use of Flue Gas Desulfurization Gypsum, Construction and Demolition Waste, and Oil Palm Waste Trunks to Produce Concrete Bricks
}

\author{
Lalitsuda Phutthimethakul ${ }^{1}$, Park Kumpueng ${ }^{1}$ and Nuta Supakata ${ }^{1,2, *}$ \\ 1 Department of Environmental Science, Faculty of Science, Chulalongkorn University, Bangkok 10330, \\ Thailand; adustilal@gmail.com (L.P.); park.kumpueng@gmail.com (P.K.) \\ 2 Waste Utilization and Ecological Risk Assessment Research Group, the Ratchadaphiseksomphot \\ Endowment Fund, Chulalongkorn University, Bangkok 10330, Thailand \\ * Correspondence: nuta.s@chula.ac.th
}

Received: 30 July 2020; Accepted: 14 August 2020; Published: 18 August 2020

\begin{abstract}
This research aims to study the utilization of waste from power plants, construction and demolition, and agriculture by varying the ratios of flue-gas desulfurization (FGD) gypsum, construction and demolition waste (CDW), and oil palm trunks (OPT) in concrete production. This research used these as the raw materials for the production of concrete bricks of $15 \times 15 \times 15 \mathrm{~cm}$. There were 12 ratios of concrete brick, fixing $5.5 \mathrm{wt} \%$ of FGD gypsum to replace Portland cement and substituting coarse sand with $0 \mathrm{wt} \%, 25 \mathrm{wt} \%, 50 \mathrm{wt} \%$, or $75 \mathrm{wt} \%$ of CDW, and gravel with $0 \mathrm{wt} \%, 0.5 \mathrm{wt} \%$, and $1 \mathrm{wt} \%$ of OPT. The initial binder:fine aggregate:coarse aggregate ratio was 1:2:4 and the water to cement ratio was 0.5 , curing in water at room temperature for 28 days. Then, all concrete brick specimens were tested for compressive strength and water absorption. From the experiment, it was found that the highest compressive strength of concrete brick specimens was $45.18 \mathrm{MPa}$, which was produced from $5.5 \%$ gypsum without CDW and OPT, while $26.84 \mathrm{MPa}$ was the lowest compressive strength obtained from concrete bricks produced from 5.5\% FGD gypsum, 75\% CDW, and 1\% OPT. In terms of usage, all proportions can be applied in construction and building work because the compressive strength and water absorption were compliant with the Thai Industrial Standard TIS 57-2530 and TIS 60-2516.
\end{abstract}

Keywords: concrete brick; FGD gypsum; construction and demolition waste; oil palm trunks

\section{Introduction}

Concrete is a mixture of ordinary Portland cement (OPC), aggregates (coarse and fine), and water; it is a common material in building construction [1]. The demand for concrete is increasing because it is very durable and cost-efficient [2]. Social and economic factors also affect the demand for concrete. Every ton of cement production releases approximately one ton of carbon dioxide into the atmosphere; this is one of the major causes of global warming [3,4]. Cement production generates up to $7 \%$ of the world's total $\mathrm{CO}_{2}$ emissions [5]. Sometimes, mineral admixtures are used as a binder in the concrete formulation to reduce the cement consumption; mostly, these come from industrial waste, which could account for $50 \%-70 \mathrm{wt} \%$ of the formula. This is one of the most effective methods of green concrete production [6-8]. The Krabi power plant is a thermal plant that uses fuel oil to generate electricity. One of the byproducts of this process is sulfur dioxide, which is generated from the sulfur contained in fuel oil and combines with oxygen during combustion [9]. Flue gas desulfurization (FGD) is the treatment used to eliminate sulfur dioxide; it produces FDG gypsum as a by-product [8]. FGD gypsum takes up a lot of space in landfills and may contaminate the surface and groundwater [8]. The main ingredient of FGD gypsum is the same as in natural gypsum [10,11], so it can be used as a substitute for 
natural gypsum in concrete production [11]. In addition, some research has found that FGD gypsum increases the hydration reaction of Portland cement [12].

The aggregate used in concrete production consists of sand, gravel, and stone [1], which are limited natural resources; there may not be enough to use them in concrete production in the future, according to the increase in demand. Therefore, some recent studies have explored alternative materials that can be substituted for natural resources in concrete production.

Construction activities increase along with population growth [13]. They generate construction and demolition waste (CDW), which is often handled inappropriately because the waste has unique characteristics, properties, and compositions that require special handling. There has been a lack of proper and comprehensive management [14]. In 2012, the generation of CDW in 40 countries worldwide reached more than three billion tons; this figure is predictedto increase rapidly $[5,15]$. However, this waste can be reused in the place of natural aggregates in construction [13], which not only reduces the amount of waste to be handled by landfills and recycling centers, but also can contribute to a circular economy. Previous studies have found that recycled CDW can be used to replace natural aggregates in concrete, replacing about $30 \%-50 \%$ of the total mass [5].

Thailand produces large amounts of agricultural waste. In 2017, Thailand had a palm oil production of around 14 million tons, of which southern Thailand contributed around 12 million tons [16]. Most of these oil palm plantations are located in four provinces in the southern part of Thailand: Krabi, Suratthani, Chumphon, and Trang, which produce approximately four million tons of palm oil per year [17]. Palm oil cultivation has also expanded from the south to other regions of Thailand. The main residues of palm oil from mills and plantations are palm kernel shells, mesocarp fibers, and empty fruit bunches [18]. When the oil palm trees are 16 years old or more, they have a decreased yield and have to be felled and replanted [19]. The felling of palm trees generates major residues such as oil palm leaves and trunks [18]. These materials can often be reused, e.g., oil palm shells are used to make a lightweight concrete [20] and empty palm bunches can be used for biomass briquettes [21], but managing oil palm trunks is difficult because they biodegrade slowly. There is research about oil palm trunk management methods such as anaerobic biodegradation [22] or use as fillers in gypsum composite [23], but there have been few studies on how to use them as an aggregate in concrete bricks. This research aims to study the utilization of waste from power plants (FGD gypsum), construction and demolition waste (CDW), and oil palm trunks (OPT) as raw materials for producing concrete bricks for the economic development of the local community in Krabi province.

\section{Materials and Methods}

\subsection{Raw Materials}

FGD gypsum was collected from the Electricity Generating Authority of Thailand (EGAT) (the Krabi power plant) and OPT was obtained from Krabi province, Thailand. CDW was obtained from the On Nut garbage disposal plant in Bangkok. Then, FGD gypsum and OPT were sun dried for five and 14 days, respectively. After drying, OPT was cut into small pieces by a grinding machine. For CDW, we reduced the size using a jaw crusher and roll crusher, and the particles were sieved through a vibration screen machine to ensure that they were the correct size, $720 \mu \mathrm{m}$ to $4.75 \mathrm{~mm}$. The chemical composition of the raw materials including OPC, FGD gypsum, coarse sand, CDW, gravel, and OPT were analyzed using an X-ray fluorescence spectrometer (S8 Tiger, Bruker, Karlsruhe, Germany). The mineralogical phase was analyzed by X-ray diffraction (XRD) (D8 Discover, Bruker, Karlsruhe, Germany). The microstructure was characterized using a scanning electron microscope (JSM-IT300, JEOL, Tokyo, Japan). The particle size of CDW, OPT, coarse sand, and gravel was verified using a laser particle distribution analyzer (Mastersizer 3000, Malvern, Malvern, UK). 


\subsection{Production of Concrete Bricks}

According to IS:456-2000 and IS:1343-1980, M15 concrete having the specified characteristic strength for 28 days at $15 \mathrm{MPa}$ [24] is the minimum grade for use as reinforced concrete. Therefore, this research used the ratio of concrete mix according to M15 concrete. The percentage replacement of fine aggregates (coarse sand) by CDW is $0 \%, 25 \%, 50 \%$, and $75 \%$, and the percentage replacement of coarse aggregates (gravel) by OPT is $0 \%, 0.5 \%$, and $1 \%$. Every proportion used FGD gypsum $5.5 \%$ to replace OPC type I. To produce concrete bricks, the mixture of each proportion has OPC and FGD gypsum as the binder, coarse sand and CDW as the fine aggregate, gravel, and OPT as the coarse aggregate, and water. The ratio of binder:fine aggregate:coarse aggregate was 1:2:4 by weight, and the ratio of binder:water was 1:0.5 by weight. All dried ingredients were mixed, then $1.5 \mathrm{~L}$ of water was added, and the mixture was stirred for $2 \mathrm{~min}$. After that, the mixture was compacted in a cube mold $(15 \times 15 \times 15 \mathrm{~cm})$ and wrapped in plastic film for $24 \mathrm{~h}$. After removing the specimen from the mold, all specimens were cured by immersion in water for 28 days at room temperature. For each proportion, we made five replicates for the compressive strength test and five replicates for the water absorption test. The proportions of concrete bricks are shown in Table 1.

Table 1. Proportions of concrete bricks. Abbreviations: CDW, construction and demolition waste; FGD, flue-gas desulfurization; OPC, ordinary Portland cement; OPT, oil palm trunks.

\begin{tabular}{|c|c|c|c|c|c|c|c|}
\hline \multirow{2}{*}{ Treatments } & \multicolumn{2}{|c|}{ Binder (\%) } & \multicolumn{2}{|c|}{ Fine Aggregate (\%) } & \multicolumn{2}{|c|}{ Coarse Aggregate (\%) } & \multirow{2}{*}{$\begin{array}{c}\text { Water/Cement } \\
\text { Ratio }\end{array}$} \\
\hline & OPC & FGD Gypsum & Coarse Sand & CDW & Gravel & OPT & \\
\hline S01 & \multirow{4}{*}{94.5} & \multirow{4}{*}{5.5} & 100 & 0 & 100 & 0 & \multirow{13}{*}{0.5} \\
\hline S02 & & & 75 & 25 & 100 & 0 & \\
\hline S03 & & & 50 & 50 & 100 & 0 & \\
\hline S04 & & & 25 & 75 & 100 & 0 & \\
\hline S05 & \multirow{4}{*}{94.5} & \multirow{4}{*}{5.5} & 100 & 0 & 99.5 & 0.5 & \\
\hline S06 & & & 75 & 25 & 99.5 & 0.5 & \\
\hline S07 & & & 50 & 50 & 99.5 & 0.5 & \\
\hline S08 & & & 25 & 75 & 99.5 & 0.5 & \\
\hline S09 & \multirow{4}{*}{94.5} & \multirow{4}{*}{5.5} & 100 & 0 & 99 & 1 & \\
\hline S10 & & & 75 & 25 & 99 & 1 & \\
\hline S11 & & & 50 & 50 & 99 & 1 & \\
\hline $\mathrm{S} 12$ & & & 25 & 75 & 99 & 1 & \\
\hline Control & 100 & 0 & 100 & 0 & 100 & 0 & \\
\hline
\end{tabular}

Then, the compressive strength and water absorption of the concrete bricks were determined according to ASTM C39 [25] and [26], respectively. The microstructure of the concrete bricks was characterized using a scanning electron microscope (JSM-IT300, JEOL, Tokyo, Japan). The mineralogical phases of the concrete bricks were identified using an X-ray diffractometer (D8 Discover, Bruker, Karlsruhe, Germany).

\subsection{Environmental and Economic Analyses}

For the environmental analysis, a comparison was made among all concrete brick treatments from S1 to $\mathrm{S} 12$ and the control. The functional unit in this study was one brick of $15 \times 15 \times 15 \mathrm{~cm}$. The system boundary was cradle-to-gate covering the raw materials acquisition, materials preparation, and concrete brick manufacturing. The life cycle assessment study was carried out using SimaPro 8.0.5.13, ReCiPe Midpoint (H) V1.06, and the World ReCiPe H method from the National Metal and Materials Technology Center (MTEC), Thailand. The results were expressed in six impact categories: abiotic depletion, acidification, global warming, ozone layer depletion, human toxicity and terrestrial ecotoxicity. 


\section{Results and Discussion}

\subsection{Characteristics of OPC, FGD Gypsum, Coarse Sand, CDW, Gravel, and OPT}

\subsubsection{Chemical Composition}

The chemical compositions of raw materials were analyzed by X-ray Fluorescence Spectrometry (S8 Tiger, Bruker, Karlsruhe, Germany), as shown in Table 2. The results showed that the major component of OPC was $\mathrm{CaO}$, while FGD gypsum had $\mathrm{SO}_{3}$ as the main component. $\mathrm{SiO}_{2}$ was the major component of coarse sand and CDW. The largest components of gravel and OPT were CaO and $\mathrm{SiO}_{2}$, respectively.

Table 2. Chemical properties of raw materials.

\begin{tabular}{ccccccc}
\hline \multirow{2}{*}{ Oxides } & \multicolumn{7}{c}{ Content (wt\%) } \\
\cline { 2 - 7 } & OPC & FGD Gypsum & Coarse Sand & CDW & Gravel & OPT \\
\hline $\mathrm{CaO}$ & 68.78 & 43.84 & 1.34 & 27.90 & 68.98 & 20.32 \\
$\mathrm{SiO}_{2}$ & 16.85 & 2.36 & 85.82 & 55.12 & 17.32 & 26.90 \\
$\mathrm{Al}_{2} \mathrm{O}_{3}$ & 4.10 & 0.88 & 7.25 & 7.74 & 5.47 & 2.22 \\
$\mathrm{SO}_{3}$ & 3.94 & 49.45 & 0.03 & 0.67 & 0.11 & 4.05 \\
$\mathrm{Fe}_{2} \mathrm{O}_{3}$ & 3.60 & 0.82 & - & 3.34 & 3.36 & 8.75 \\
$\mathrm{MgO}$ & 1.30 & 1.79 & 0.21 & 1.56 & 2.20 & 3.09 \\
$\mathrm{~K}_{2} \mathrm{O}$ & 0.54 & 0.14 & 4.47 & 2.67 & 1.88 & 22.75 \\
$\mathrm{TiO}_{2}$ & 0.28 & 0.03 & 0.16 & 0.36 & 0.30 & 0.47 \\
\hline
\end{tabular}

\subsubsection{Particle Sizes}

The particle size of the fine aggregate and coarse sand was more evenly distributed than in CDW but all passed through a $4.75 \mathrm{~mm}$ sieve and were retained on a $0.075 \mathrm{~mm}$ sieve, which was the size range specified for fine aggregate. The most common particle size of coarse sand was $0.850 \mathrm{~mm}$, while for CDW it was $1.00 \mathrm{~mm}$. The particle size distribution of the coarse aggregate was ostensibly different. The particle size of gravel was $5.60 \mathrm{~mm}$ and for OPT it was $0.71 \mathrm{~mm}$, as shown in Figure 1.
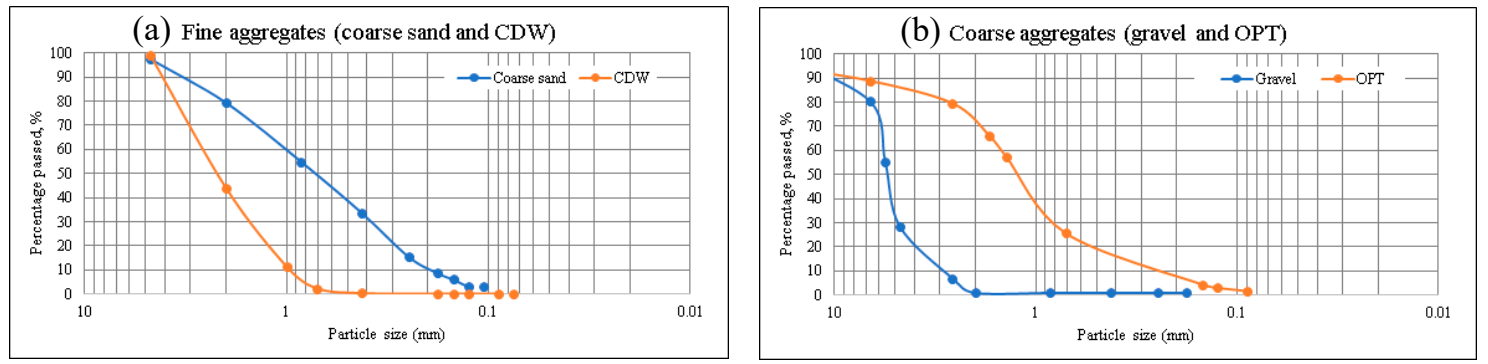

Figure 1. The particle size of the raw materials: (a) fine aggregates; (b) coarse aggregates.

\subsubsection{The Mineralogical Phase}

The results showed that the major crystalline phases of OPC and FGD gypsum were calcium silicate oxide $\left(\mathrm{Ca}_{2} \mathrm{SiO}_{4}\right)$ and calcium sulfate dihydrate $\left(\mathrm{CaSO}_{4} \cdot 2 \mathrm{H}_{2} \mathrm{O}\right)$, respectively. Quartz $\left(\mathrm{SiO}_{2}\right)$ was the major crystalline phase of coarse sand, CDW, gravel, and OPT, as shown in Figure 2. 

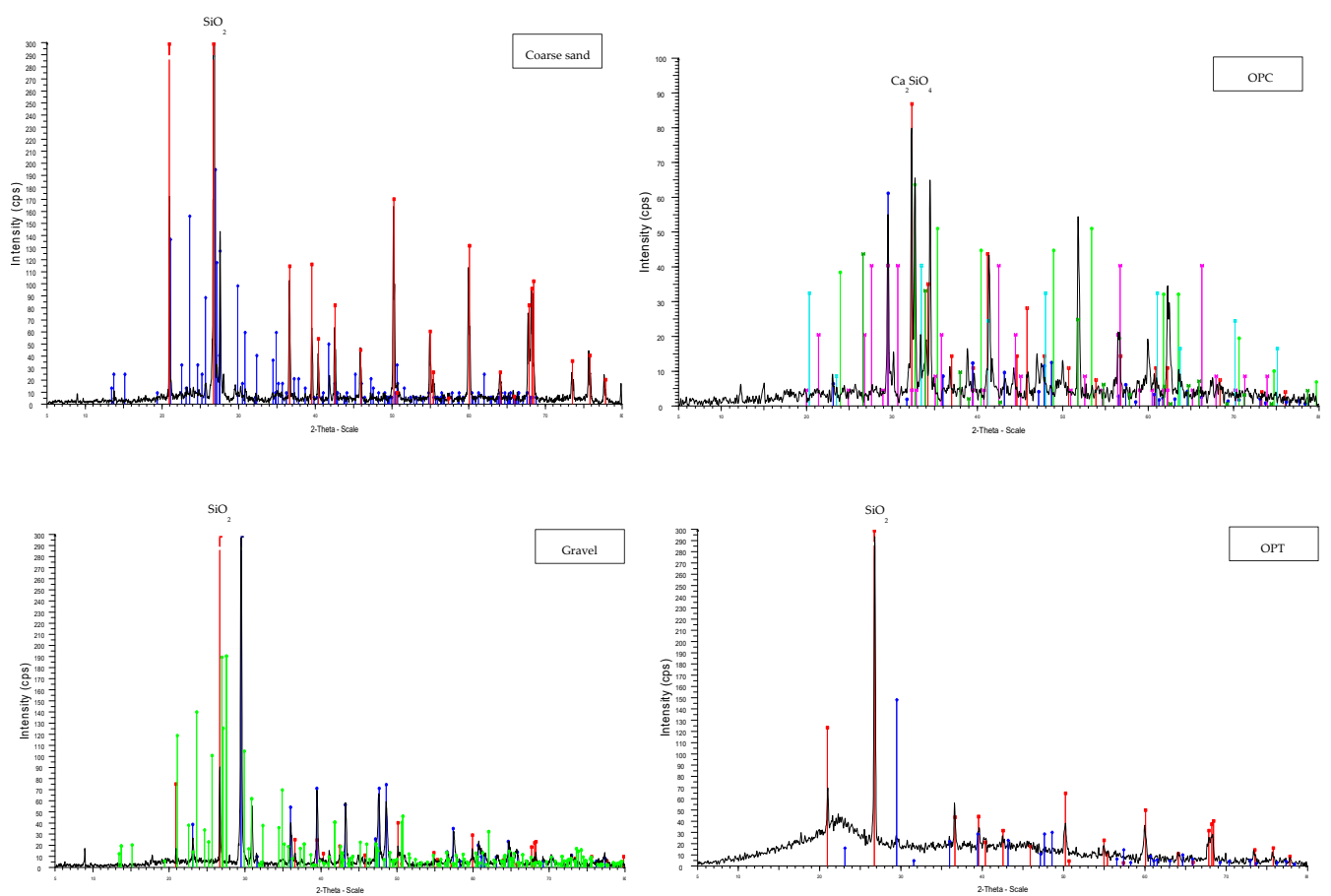

Figure 2. X-ray diffractometer (XRD) pattern of raw materials.

\subsubsection{Microstructures of the Raw Materials}

As shown in Figure 3, the particle morphologies of OPC were plate-shaped and smaller than FGD gypsum, while FGD gypsum had a columnar shape and smooth surface appearance. The main components of OPC and FGD gypsum were oxygen and calcium. The particle morphologies of coarse sand were an irregular angular shape and had a smoother surface than CDW, while CDW had a large size, highly irregular angles, and rough surface. Oxygen was the main element in both coarse sand and $\mathrm{CDW}$, but the minor element of coarse sand was silicon, while for CDW it was carbon. The particle morphologies of gravel and OPT had a rough surface, but OPT also had a layer stacked on the surface. OPT had only two elements, carbon and oxygen, while oxygen was the major element and carbon was a minor element of gravel.
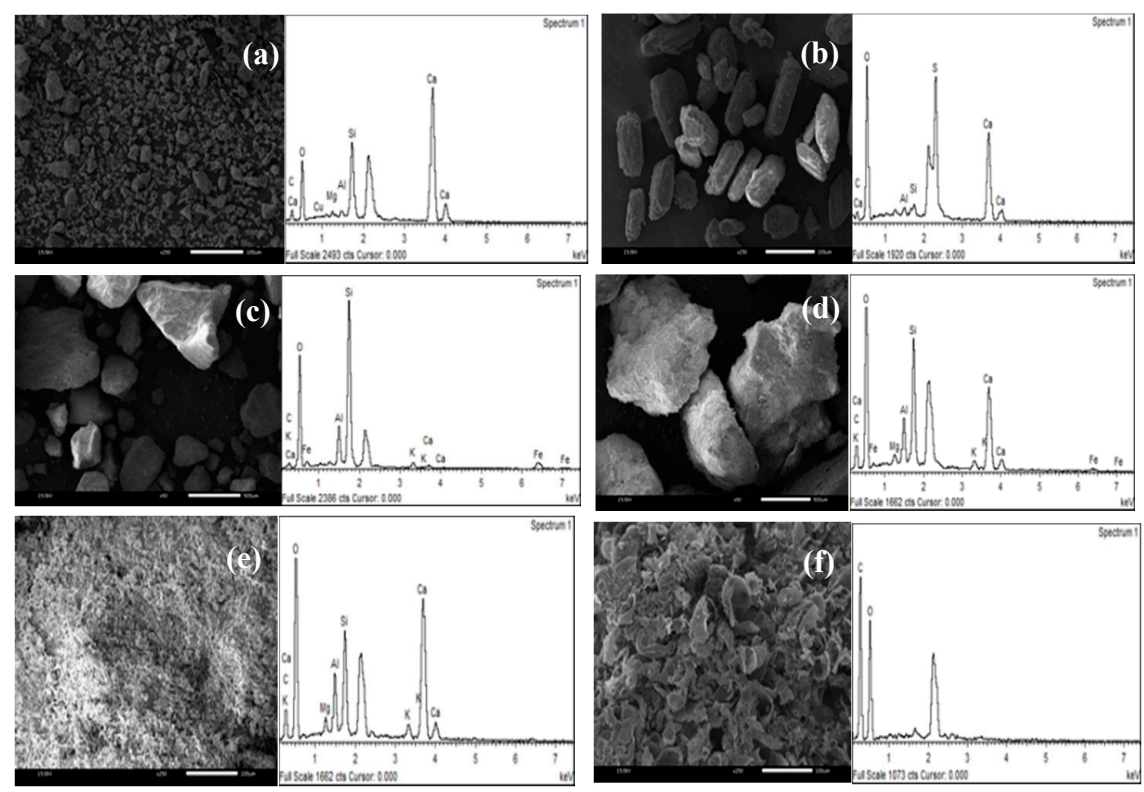

Figure 3. Microstructures of (a) OPC; (b) FGD gypsum; (c) coarse sand; (d) CDW; (e) gravel; and (f) OPT. 


\subsection{Characteristics of Concrete Bricks Made from OPC, FGD Gypsum, Coarse Sand, CDW, Gravel, and OPT}

The concrete brick can be divided into three groups; Group 1 was a representative of concrete bricks without OPT including S01, S02, S03, and S04; Group 2 was S05, S06, S07, and S08, which were the concrete bricks with OPT $0.5 \%$. The concrete bricks that used OPT $1 \%$ were S09, S10, S11, and S12, together called Group 3. In each group, there was a difference in the amount of replacement of fine aggregate by $0 \%, 25 \%, 50 \%$, and $75 \%$ of CDW.

\subsubsection{General Appearance of Concrete Bricks}

The general appearances of concrete bricks were similar in all proportions, as shown in Figure 4. The surface of concrete bricks was not smooth due to the connection between cement paste and aggregate being incomplete. More voids were found in concrete bricks with a higher amount of OPT due to the different size of coarse aggregate particles between gravel and OPT.
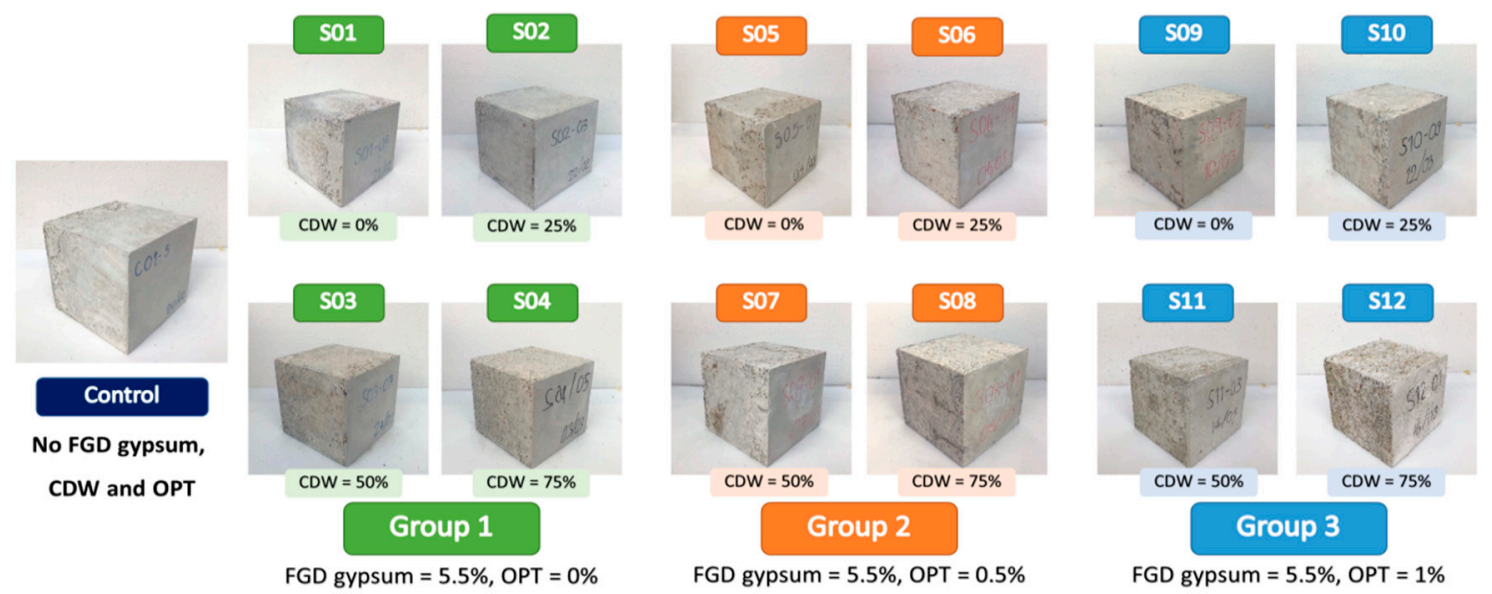

Figure 4. The appearance of the concrete bricks.

\subsubsection{Compressive Strength of Concrete Bricks}

Concrete brick specimen S01 produced from 5.5\% FGD gypsum without CDW and OPT cured at 28 days obtained the highest compressive strength (45.18 MPa), while concrete brick specimen S12 produced from 5.5\% FGD gypsum, 75\% CDW, and 1\% OPT obtained the lowest compressive strength $(26.84 \mathrm{MPa})$. As shown in Figure 5, the compressive strength of concrete bricks decreased when higher amounts of CDW and OPT were added to the concrete mix. From the results of this study, the compressive strength of all specimens was higher than the compressive strength required by the standards of hollow load-bearing concrete masonry units (TIS 57-2530 all types, $\geq 5 \mathrm{MPa}$ ) [27] and solid load-bearing concrete masonry units (TIS 60-2516 all types, $\geq 8.34 \mathrm{MPa}$ ) [28]. Thus, the results of this study can be applied in production of concrete masonry blocks especially in masonry wall construction of 15 to $20 \mathrm{MPa}$ [29-31].

\subsubsection{Water Absorption}

Concrete brick specimen S12 produced from 5.5\% FGD gypsum, 75\% CDW, and 1\% OPT (with the highest amount of CDW and OPT) cured at 28 days obtained the highest water absorption $\left(111.4 \mathrm{~kg} / \mathrm{m}^{3}\right)$, while concrete brick specimen S01 produced from 5.5\% FGD gypsum without CDW and OPT (excluding control) obtained the lowest water absorption $\left(78 \mathrm{~kg} / \mathrm{m}^{3}\right)$. As shown in Figure 6, the more CDW and OPT that were added, the more the water absorption increased. In addition, all concrete brick specimens were water absorption compliant, as defined by both standards $\left(160 \mathrm{~kg} / \mathrm{m}^{3}\right)[27,28]$. 


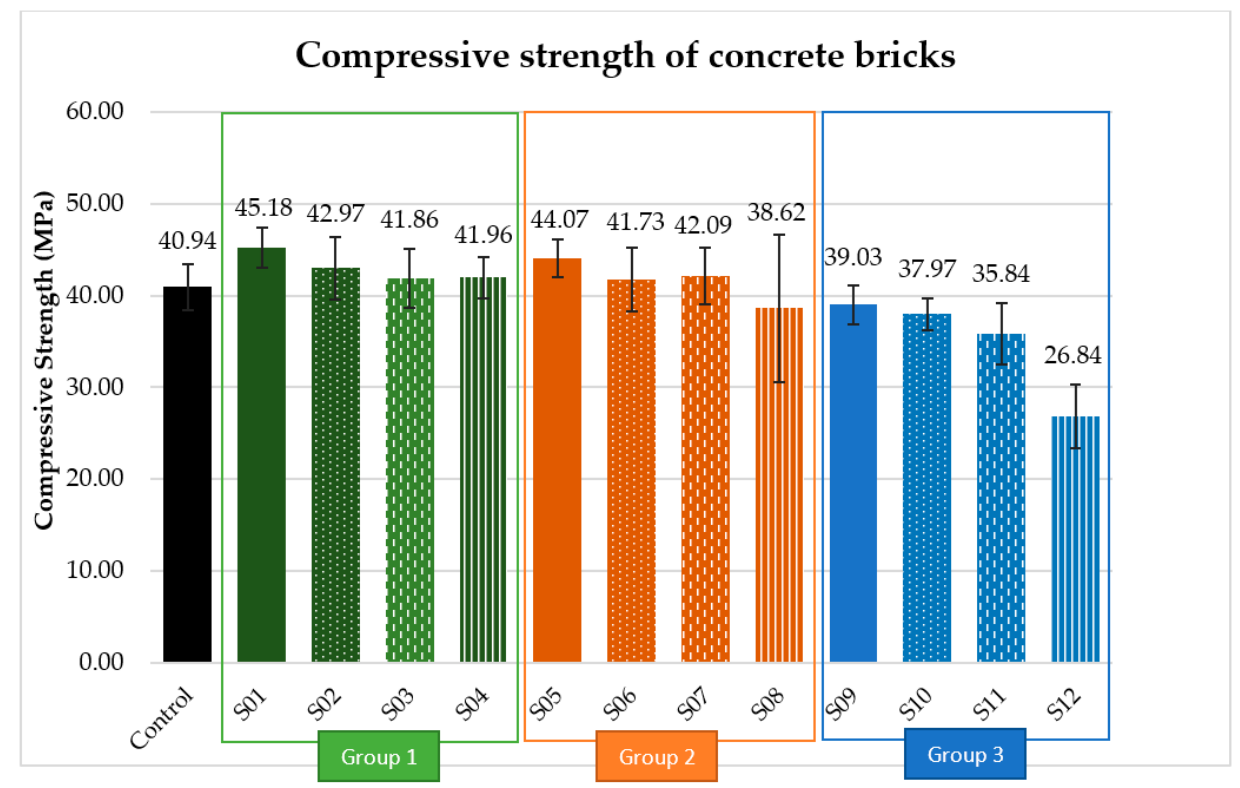

Figure 5. The compressive strength of concrete bricks.

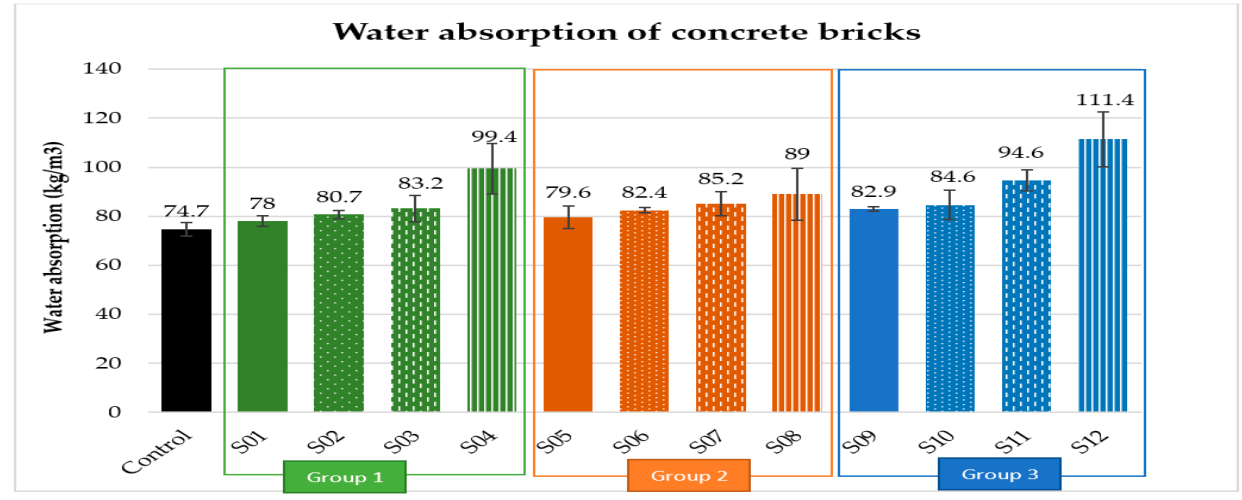

Figure 6. The water absorption of concrete bricks.

According to the compressive strength and water absorption analysis, concrete bricks with higher amounts of CDW and OPT had a lower compressive strength and higher water absorption, especially concrete brick specimen S12 (75\% CDW and 1\% OPT), which had the lowest compressive strength and the highest water absorption, while concrete brick specimen S01, produced from 5.5\% FGD gypsum without CDW and OPT, had the highest compressive strength and the lowest water absorption. Figure 7 shows a cross section of the concrete brick specimen; the left side of Figure 7 represents a control concrete brick without CDW and OPT, having coarse sand $(0.85 \mathrm{~mm})$ as the fine aggregate and gravel $(5.60 \mathrm{~mm})$ as the coarse aggregate, with the same particle size as coarse sand as the fine aggregate can fill the gaps in gravel as coarse aggregate. The center image in Figure 7 represents a concrete brick having CDW $(1.00 \mathrm{~mm})$ replacing $25 \%-100 \%$ of coarse sand; the particle size of CDW is larger than that of coarse sand, and the particles were arranged in a disorderly manner in concrete brick specimens, causing more porosities and large voids that resulted in decreasing compressive strength and increasing water absorption when a higher amount of CDW was added. The right side of Figure 7 represents a concrete brick having CDW replacing $25 \%-100 \%$ of coarse sand and OPT replacing $0.5 \%-1 \%$ of gravel; vegetal particles like OPT tend to detach from the OPC binder because of the deficient cohesion, chemical incompatibility, and dissolution of hydration products, causing an increase in water absorption [32] and a decrease in compressive strength when a higher amount of OPT is added. According to Diquélou et al. (2015) and Dinh (2014) [33,34], the addition of plant aggregates (corn stalk, lavender stalk, and hemp shiv) decreased the products of hydration, including 
calcium silicate hydrate $(\mathrm{CSH})$ and calcium hydroxide $(\mathrm{CH})$. Moreover, the different size of coarse aggregate between gravel $(5.60 \mathrm{~mm})$ and OPT $(0.71 \mathrm{~mm})$ created porosity in concrete bricks, resulting in decreased compressive strength and increased water absorption.

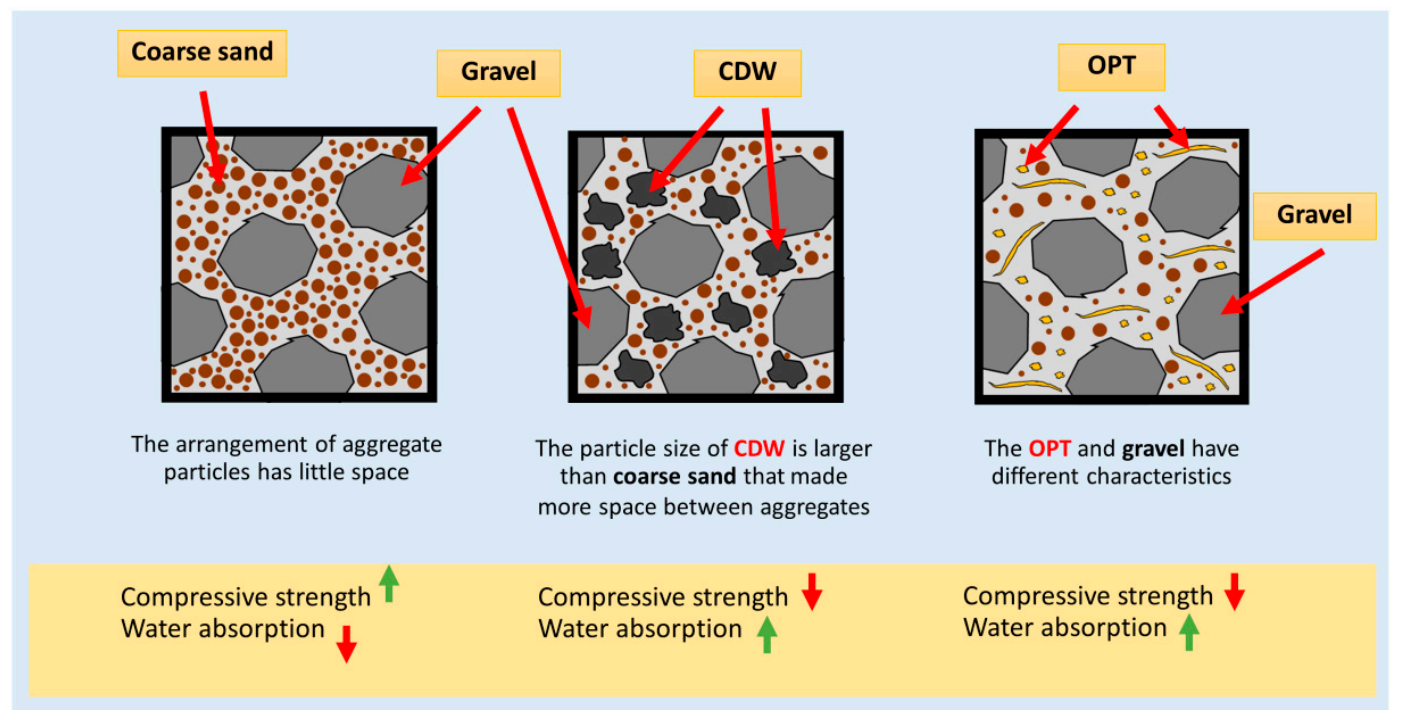

Figure 7. Cross sections of concrete brick specimens.

\subsubsection{Mineralogical Phases of Concrete Bricks}

The X-ray diffraction patterns of concrete brick after 28 days of curing were analyzed (D8 Discover, Bruker, Karlsruhe, Germany). The results are shown in Figure 8. The mineralogical phases of all concrete bricks were similar. All of the samples had intense peaks around $29.2^{\circ}(2 \theta)$, which is both $\mathrm{CSH}$ and calcite. Other peaks of CSH were indicated at $42.7^{\circ}$ and $55.3^{\circ}(2 \theta)$ [35].

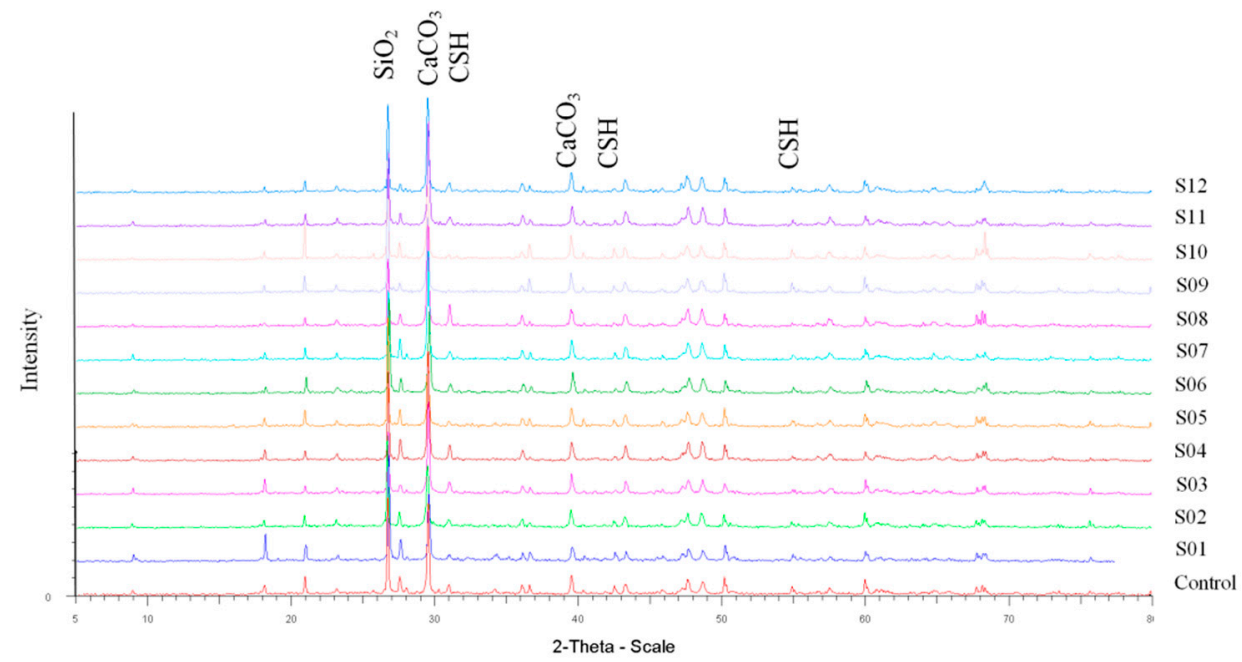

Figure 8. The X-ray diffraction patterns of concrete bricks. CSH: calcium silicate hydrate.

\subsubsection{Microstructure of Concrete Bricks}

The microstructure of concrete bricks was identified by a Scanning Electron Microscope (JSM-IT300, JEOL, Tokyo, Japan) ( $\times 1500$ magnification). The element compositions of concrete brick were identified by an Energy-Dispersive X-ray Spectrometer (JSM-IT300, JEOL, Tokyo, Japan). As shown in Figure 9, ettringite, the insoluble calcium layer formed by the reaction of gypsum with tricalcium aluminate $\left(C_{3} A\right)$, was obviously found in $\mathrm{S} 04$ and $\mathrm{S} 09$ on the aggregate surface due to the hydration reaction. The ettringite was a needle-shaped crystal caused by sulfate ions of gypsum reacting with $\mathrm{C}_{3} \mathrm{~A}$ and 
water. Most hydration reaction products consisted of calcium silicate hydrate (CSH), calcium hydroxide $(\mathrm{CH})$, and ettringite, which filled the gap. $\mathrm{CSH}$ had a jelly-like function, to combine the aggregate.
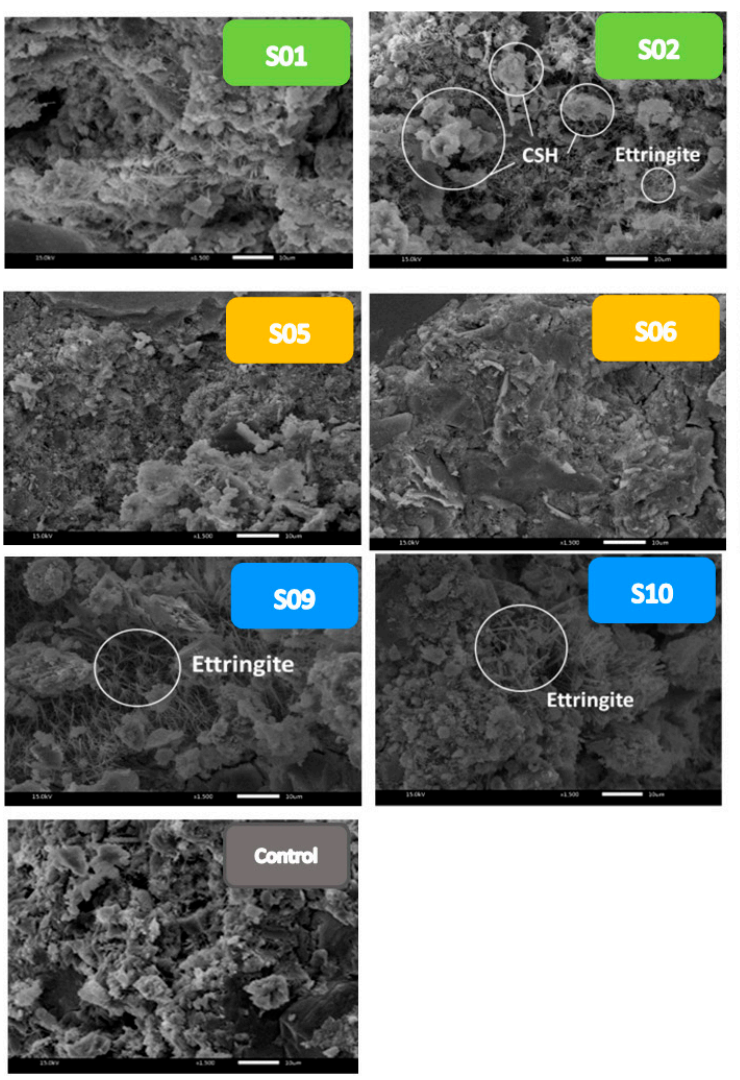


Figure 9. The microstructures of concrete bricks.

Considering the utilization of agricultural and industrial wastes as raw materials for concrete brick production, all proportions can be applied in construction and building activities because the compressive strength and water absorption of all concrete brick specimens in this study were compliant with the requirements. Furthermore, the X-ray diffraction pattern, microstructure, and element compositions showed that all of the concrete brick proportions had similar characteristics. To provide recommendations for how concrete brick manufacturing can be more eco-friendly, the environmental impact of the concrete brick made from FGD gypsum, construction and demolition waste, and oil palm trunks was analyzed in terms of abiotic depletion, acidification, global warming, ozone layer depletion, human toxicity and terrestrial ecotoxicity. In addition, the economic feasibility of the concrete bricks was studied and the results are given in Section 3.3.

\subsection{Life Cycle Assessment and Economic Feasibility of Concrete Bricks Made from OPC, FGD Gypsum, Coarse Sand, CDW, Gravel, and OPT}

The processes of concrete brick production consisted of raw material acquisition, raw material preparation, and brick manufacturing. The impact was calculated and converted into an equivalent factor to calculate the total impact in each category. Concrete brick production of 12 ratios (S01-S12) was divided into three groups differentiated by percent of OPT: S01-S04 used OPT as gravel substitution by $0 \%$, S05-S08 by $0.5 \%$, and S09-S12 by $1 \%$, respectively. Within the group, the concrete brick CDW ratios also varied between $25 \%, 50 \%$, and $75 \%$, while the amount of FGD gypsum was fixed at $5.5 \%$ for all ratios. Control samples of concrete brick production were produced from OPC, sand, and gravel, which are the common materials used in construction work. The impact category of concrete brick production was compared between each ratio using S12 concrete brick production to represent $100 \%$ of emissions. The impacts of the concrete production tended to be higher due to the substitution of fine 
aggregates by construction and demolition waste at $25 \%, 50 \%$, or $75 \%$ in S04, S08, and S12, respectively, as shown in Figure 10. The impacts from CDW were caused by the raw materials acquisition and preparation, e.g., diesel as a fuel for transportation and electricity for crushing, grinding, and screening the CDW [36]. Moreover, the substitution of coarse aggregate by oil palm trunks (OPT) had an impact on concrete brick production due to the OPT being transported to the experiment site by truck and the preparation needing shredding, which used diesel and electricity, respectively.

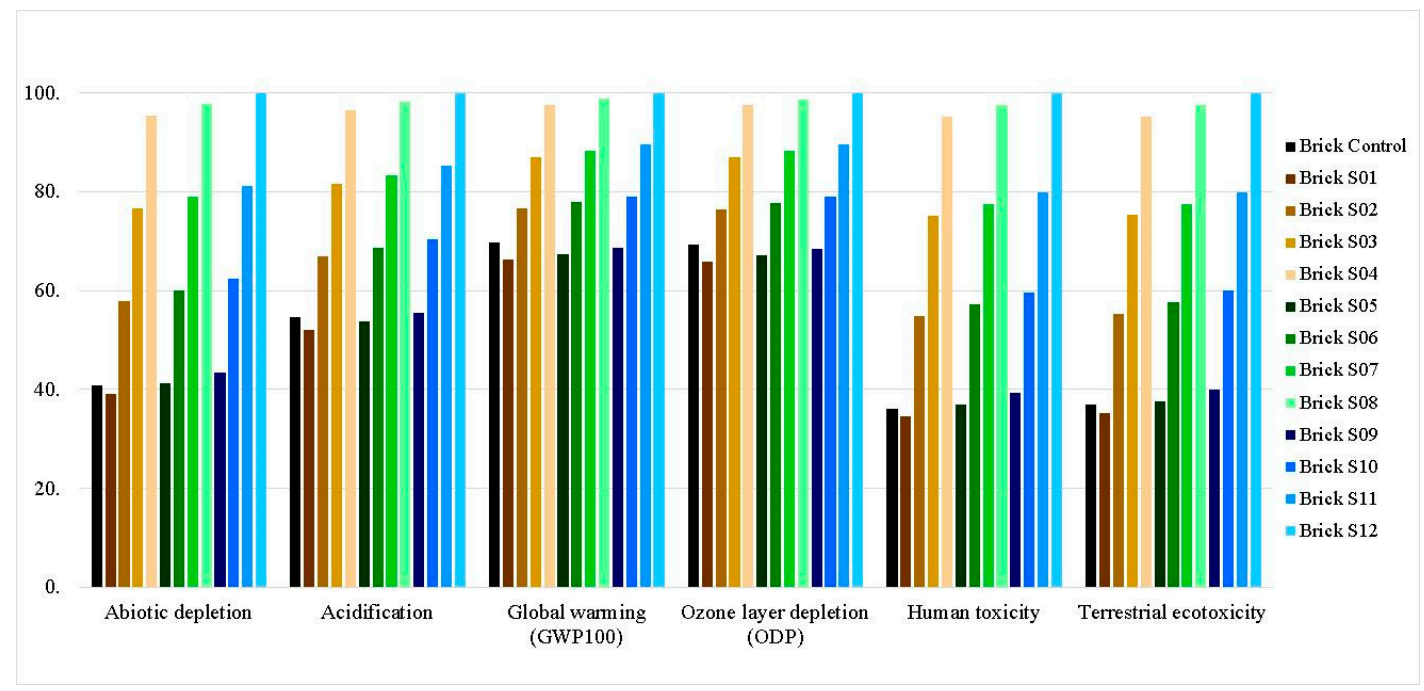

Figure 10. The comparative environmental impacts of concrete brick production of each ratio.

According to the results, most of the environmental impacts were directly related to the volume of aggregates being substituted. The more construction and demolition waste and oil palm trunks that were used, the more the environmental impacts of the concrete brick production increased due to the preparation of CDW and OPT consuming a high amount of electricity.

In this research, economic feasibility is divided into two case studies. First, the S01 concrete brick production produced from 5.5\% FGD gypsum without CDW and OPT had the best physical properties including compressive strength, water absorption, and density. Second was S12 produced from 5.5\% FGD gypsum, 75\% CDW, and 1\% OPT, which used the highest amount of recycled waste as a substitution in brick production. The comparison of the economic feasibility of concrete brick production between S01 and S12 showed that S12 concrete brick production (fixed cost: 226,000 Baht and variable cost: 17.57 Baht/piece) was higher than the S01 concrete brick production (fixed cost: 48,000 Baht and variable cost: $16.56 \mathrm{Baht} /$ piece) due to the raw material preparation, which required machinery and high electricity consumption for material preparation, as shown in Figure 11.
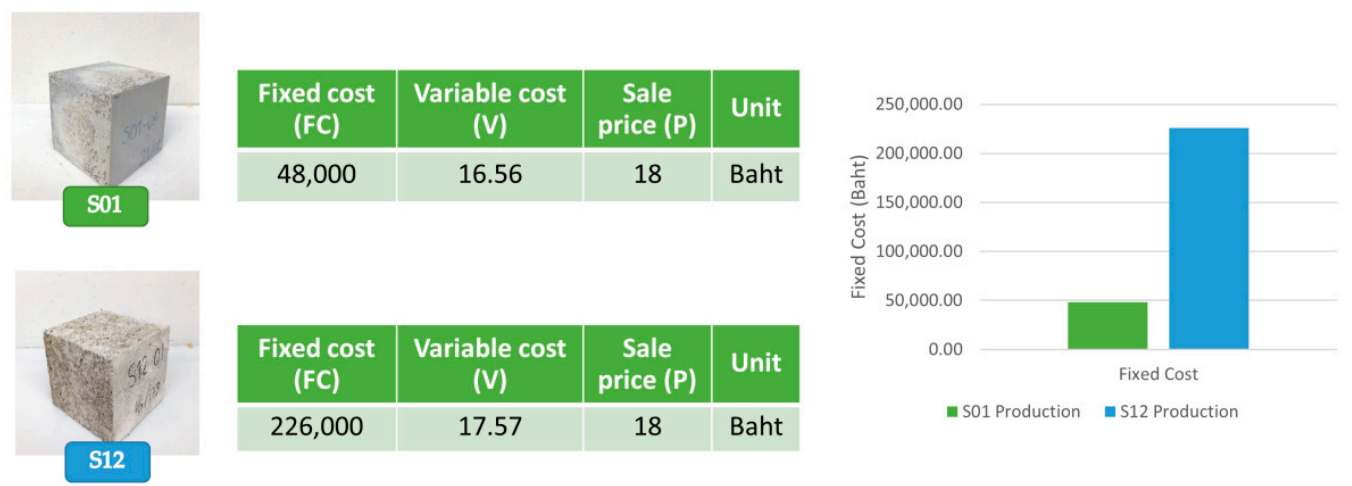

Figure 11. Cost comparison of the brick production between S01 and S12. 
The breakeven point of S01 concrete brick production is 33,333 pieces, which is lower than the $\mathrm{S} 12$ concrete brick production of 528,581.4 pieces due to the lower capital from the production causing the payback period of $\mathrm{S} 12$ concrete brick production ( 3.383 years) to be higher than that of $\mathrm{S} 01$ concrete brick production (0.213 years) at the same sale price (18 Baht/piece), as shown in Figure 12.
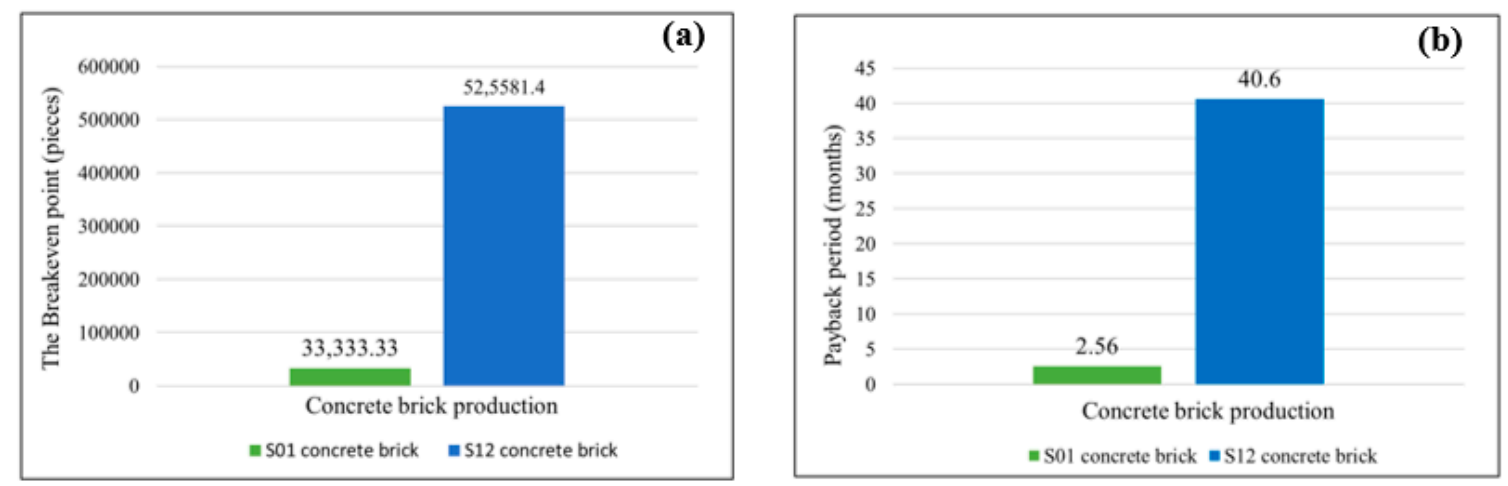

Figure 12. (a) Breakeven point comparison of brick production between S01 and S12; (b) payback period comparison of brick production between S01 and S12.

\section{Conclusions}

This study focused on the utilization of waste from power plants, construction and demolition waste, and agricultural wastes. The experiment was conducted to determine the utilization of FGD gypsum, construction and demolition waste (CDW), and oil palm trunks (OPT) for concrete brick production. The results found that the optimal ratio of concrete brick leading to the highest compressive strength was in concrete brick specimen S01. The main conclusions are summarized as follows:

1. Concrete brick specimen S01 produced from 5.5\% FGD gypsum without CDW and OPT cured at 28 days obtained the highest compressive strength (45.18 MPa), while concrete brick specimen S12 produced from 5.5\% FGD gypsum, 75\% CDW, and 1\% OPT obtained the lowest compressive strength (26.84 MPa).

2. Adding only FGD gypsum in the production of concrete brick specimens showed that the compressive strength of these specimens increased with significant differences when compared to the compressive strength of the control.

3. Using CDW and OPT led to similar effects: increasing CDW and OPT reduced the compressive strength and increased the water absorption of concrete bricks.

4. All of the concrete brick proportions had compressive strength and water absorption that were compliant with the requirements of TIS 57-2530 and TIS 60-2516; thus, CDW, OPT, and FGD gypsum can be used as raw materials for bearing concrete masonry units.

5. A comparison of the environmental impacts of concrete brick production showed that the production of S01 concrete bricks made with 5.5\% FGD gypsum without CDW and OPT involved the lowest emissions. On the other hand, S12 concrete brick production led to the highest emissions due to the concrete bricks being made with 5.5\% FGD gypsum, 75\% CDW, and 1\% OPT.

6. The S01 concrete brick production had the shortest payback period due to the lower cost of the raw material preparation process, which does not require machinery for grinding and sieving.

The authors would like to recommend that the size of concrete bricks/blocks made from these wastes can be differed to suit the construction practices. The compressive strength of concrete bricks in this study is high which can be used in the production of hollow blocks used to accommodate reinforcement in the walls for increased earthquake and lateral load resistance. To apply this in building and construction works, mechanical characteristics such as tensile strength, elastic modulus, stress-strain curves should be examined for future study. 
Author Contributions: Conceptualization, N.S.; methodology, N.S., L.P., and P.K.; validation, N.S.; formal analysis, L.P. and P.K.; investigation, L.P. and P.K.; resources, N.S.; data curation, N.S., L.P., and P.K.; writing-original draft preparation, L.P. and P.K.; writing—review and editing, N.S.; visualization, N.S.; supervision, N.S.; project administration, N.S.; funding acquisition, N.S. All authors have read and agreed to the published version of the manuscript.

Funding: This research was funded by the Electricity Generating Authority of Thailand, grant number 62-F10700011-IO.SS03F3008435. APC was funded by the Ratchadaphiseksomphot Endowment Fund.

Acknowledgments: The authors would like to thank Damrong Saiya, Chaiwat Boonroeang Kaow, Prapakorn Thachapradit, Sirikan Sawangsawai, and Awika Numnual from Electricity Generating Authority of Thailand (EGAT) (The Krabi power plant) for their support. The authors gratefully acknowledge the Department of Environmental Science in the Faculty of Science, the Department of Mining Engineering, the Department of Civil Engineering, and the Center of Laboratory Engineering in the Faculty of Engineering, the Environmental Research Institute and the Scientific and Technological Research Equipment Centre (STREC) for providing mechanical equipment, Electricity Generating Authority of Thailand (EGAT) (The Krabi power plant) for providing FGD gypsum and OPT, and On Nut garbage disposal plant in Bangkok for providing the CDW used in this investigation. The authors gratefully acknowledge Seksan Papong and the National Metal and Materials Technology Center for the database and software used in this investigation. The authors would also like to thank Sarawut Srithongouthai, Vorapot Kanokantapong, Chidsanuphong Chart-asa, and Nuttakorn Intaravicha for their kind suggestions.

Conflicts of Interest: The authors declare no conflict of interest.

\section{References}

1. Verian, K.P.; Ashraf, W.; Cao, Y. Properties of recycled concrete aggregate and their influence in new concrete production. Resour. Conserv. Recycl. 2018, 133, 30-49. [CrossRef]

2. Medina, C.; Zhu, W.; Howind, T.; Frías, M.; De Sánchez Rojas, M.I. Effect of the constituents (asphalt, clay materials, floating particles and fines) of construction and demolition waste on the properties of recycled concretes. Constr. Build. Mater. 2015, 79, 22-33. [CrossRef]

3. Ahmari, S.; Ren, X.; Toufigh, V.; Zhang, L. Production of geopolymeric binder from blended waste concrete powder and fly ash. Constr. Build. Mater. 2012, 35, 718-729. [CrossRef]

4. Mo, K.H.; Johnson, A.U.; Jumaat, M.Z.; Yap, S.P. Feasibility study of high volume slag as cement replacement for sustainable structural lightweight oil palm shell concrete. J. Clean. Prod. 2015, 91, 297-304. [CrossRef]

5. Akhtar, A.; Sarmah, A.K. Construction and demolition waste generation and properties of recycled aggregate concrete: A global perspective. J. Clean. Prod. 2018, 186, 262-281. [CrossRef]

6. Van Den Heede, P.; De Belie, N. Environmental impact and life cycle assessment (LCA) of traditional and "green" concretes: Literature review and theoretical calculations. Cem. Concr. Compos. 2012, 34, 431-442. [CrossRef]

7. Igliński, B.; Buczkowski, R. Development of cement industry in Poland-History, current state, ecological aspects. A review. J. Clean. Prod. 2017, 141, 702-720. [CrossRef]

8. Jiang, L.; Li, C.; Wang, C.; Xu, N.; Chu, H. Utilization of flue gas desulfurization gypsum as an activation agent for high-volume slag concrete. J. Clean. Prod. 2018, 205, 589-598. [CrossRef]

9. Nikhom, S. Characterization of Gypsum Paste Using Flue Gas Desulfurization Sludge, Rubber Wood Fly Ash and Kaolin. Master's Thesis, Department of Civil Engineering (Structural Enginner), Prince of Songkla University, Songkhla, Thailand, 2010.

10. Lei, D.Y.; Guo, L.P.; Sun, W.; Liu, J.P.; Miao, C.W. Study on properties of untreated FGD gypsum-based high-strength building materials. Constr. Build. Mater. 2017, 153, 765-773. [CrossRef]

11. Caillahua, M.C.; Moura, F.J. Technical feasibility for use of FGD gypsum as an additive setting time retarder for Portland cement. J. Mater. Res. Technol. 2018, 7, 190-197. [CrossRef]

12. Poon, C.S.; Qiao, X.C.; Lin, Z.S. Effects of flue gas desulphurization sludge on the pozzolanic reaction of reject-fly-ash-blended cement pastes. Cem. Concr. Res. 2004, 34, 1907-1918. [CrossRef]

13. Fatemi, S.; Imaninasab, R. Performance evaluation of recycled asphalt mixtures by construction and demolition waste materials. Constr. Build. Mater. 2016, 120, 450-456. [CrossRef]

14. Kongchuenak, S. Legal Measures for Recycling of Construction and Demolition Waste: A Comparative Study between Thailand and Japan. Master's Thesis, Department of Natural Resources and Environmental Law, Faculty of Law, Thammasat University, Pathumthani, Thailand, 2016.

15. Hu, K.; Chen, Y.; Naz, F.; Zeng, C.; Cao, S. Separation studies of concrete and brick from construction and demolition waste. Waste Manag. 2019, 85, 396-404. [CrossRef] [PubMed] 
16. Office of Agricultural Economics. Summary of Oil Palm Production in 2017. Available online: http: //www.oae.go.th/assets/portals/1/fileups/prcaidata/files/oilpalm60_dis.pdf (accessed on 10 June 2019).

17. Agricultural Research Development Agency. Oil Palm Production in Southern Thailand. Available online: http://www.arda.or.th/kasetinfo/south/palm/controller/01-12.php (accessed on 9 June 2019).

18. Abnisa, F.; Arami-Niya, A.; Wan Daud, W.M.A.; Sahu, J.N.; Noor, I.M. Utilization of oil palm tree residues to produce bio-oil and bio-char via pyrolysis. Energy Convers. Manag. 2013, 76, 1073-1082. [CrossRef]

19. Oil Palm Agronomical Research Center. Oil Palm Tree: The Propagation, Plantation Management; Knowledge book Series; Prince of Songkla University: Songkhla, Thailand, 2010; pp. 71-73.

20. Traore, Y.B.; Messan, A.; Hannawi, K.; Gerard, J.; Prince, W.; Tsobnang, F. Effect of oil palm shell treatment on the physical and mechanical properties of lightweight concrete. Constr. Build. Mater. 2018, 161, 452-460. [CrossRef]

21. Srisang, N.; Srisang, S.; Wongpitithawat, P.; The-Eye, K.; Wongkeaw, K.; Sinthoo, C. Production of Biomass Briquette from Residual Bleaching Earth and Empty Palm Bunch. Energy Procedia 2017, 138, 1079-1084. [CrossRef]

22. Widyasti, E.; Shikata, A.; Hashim, R.; Sulaiman, O.; Sudesh, K.; Wahjono, E.; Kosugi, A. Biodegradation of fibrillated oil palm trunk fiber by a novel thermophilic, anaerobic, xylanolytic bacterium Caldicoprobacter sp. CL-2 isolated from compost. Enzym. Microb. Technol. 2018, 111, 21-28. [CrossRef]

23. Selamat, M.E.; Hashim, R.; Sulaiman, O.; Kassim, M.H.M.; Saharudin, N.I.; Taiwo, O.F.A. Comparative study of oil palm trunk and rice husk as fillers in gypsum composite for building material. Constr. Build. Mater. 2019, 197, 526-532. [CrossRef]

24. Gambhir, M.L. Grades of Concrete. In Concrete Technology, 3rd ed.; McGraw-Hill Publishing Co. Ltd.: New York, NY, USA, 2004; pp. 5-6.

25. ASTM C39/39M-18. Standard Test Method for Compressive Strength of Cylindrical Concrete Specimens; ASTM International: West Conshohocken, PA, USA, 2016.

26. ASTM C642-13. Standard Test Method for Density, Absorption, and Voids in Hardened Concrete; ASTM International: West Conshohocken, PA, USA, 2013.

27. TIS 57-2530. Standard for hollow load-bearing concrete masonry units. In Thailand Industrial Standard; Ministry of Industry: Bangkok, Thailand, 1990.

28. TIS 60-2516. Standard for solid load-bearing concrete masonry units. In Thailand Industrial Standard; Ministry of Industry: Bangkok, Thailand, 1973.

29. Li, D.; Zhuge, Y.; Gravina, R.; Mills, J.E. Compressive stress strain behavior of crumb rubber concrete (CRC) and application in reinforced CRC slab. Constr. Build. Mater. 2018, 166, 745-759. [CrossRef]

30. Zahra, T.; Dhanasekar, M. Prediction of masonry compressive behaviour using a damage mechanics inspired modelling method. Constr. Build. Mater. 2016, 109, 128-138. [CrossRef]

31. Mohamad, G.; Lourenço, P.B.; Roman, H.R. Mechanics of hollow concrete block masonry prisms under compression: Review and prospects. Cem. Concr. Compos. 2007, 29, 181-192. [CrossRef]

32. Ahmad, M.R.; Chen, B. Influence of type of binder and size of plant aggregate on the hygrothermal properties of bio-concrete. Constr. Build. Mater. 2020, 251, 1-14. [CrossRef]

33. Diquélou, Y.; Gourlay, E.; Arnaud, L.; Kurek, B. Impact of hemp shiv on cement setting and hardening: Influence of the extracted components from the aggregates and study of the interfaces with the inorganic matrix. Cem. Concr. Compos. 2015, 55, 112-121. [CrossRef]

34. Dinh, T.M. Contribution to the Development of Precast Hempcrete Using Innovative Pozzolanic Binder; University of Toulouse: Toulouse, France, 2014.

35. Hunnicutt, W. Characterization of Calcium-Silicate-Hydrate and Calcium-Alumino-Silicate-Hydrate. Master's Thesis, Department of Civil Engineering. Graduate College, University of Illinois at Urbana-Champaign, Urbana, IL, USA, 2013.

36. Afkhami, B.; Akbarian, B.; Beheshti, A.N.; Kakaee, A.H.; Shabani, B. Energy consumption assessment in a cement production plant. Sustain. Energy Technol. Assess. 2015, 10, 84-89. [CrossRef]

(C) 2020 by the authors. Licensee MDPI, Basel, Switzerland. This article is an open access article distributed under the terms and conditions of the Creative Commons Attribution (CC BY) license (http://creativecommons.org/licenses/by/4.0/). 